\title{
Editorial
}

\section{Dubai \\ Medical Journal}

\section{Editorial}

Our scope is to encourage innovative research by promoting original scientific research in the fields of medicine, health sciences, nursing, pharmaceuticals, and laboratory and other related sciences. Nonclinical subjects related to medicine, especially ethics and complementary medicine as well as social and cultural issues, are also covered. As international as Dubai itself, the journal offers a global perspective but also focuses on the United Arab Emirates. Partnerships with local and international medical and health authorities are envisaged.

The journal facilitates the dissemination of information through research articles, review articles, case reports, editorials, letters, book reviews, meeting reports, and discussions. An educational corner will help to ensure continuous professional development and education. Besides this, the journal also offers a platform for controversies, mythology, and much more.

We aim to be a leading journal in the region and one to be considered for publication of state-of-the-art research articles as we count on an outstanding international advisory board and editors. The editors will publish evidencebased medicine and reviews from experts in the field. Dubai Medical Journal plans to be a source of high-quality information, based on the publication of peer-reviewed original articles, which ensures the integrity of researchers and of research work.

I would like to invite all our future authors to submit their papers via our website: https://www.karger.com/Journal/Home/277043.

Patricio M. Aduriz-Lorenzo

\section{KARGER}

(C) 2018 The Author(s) 